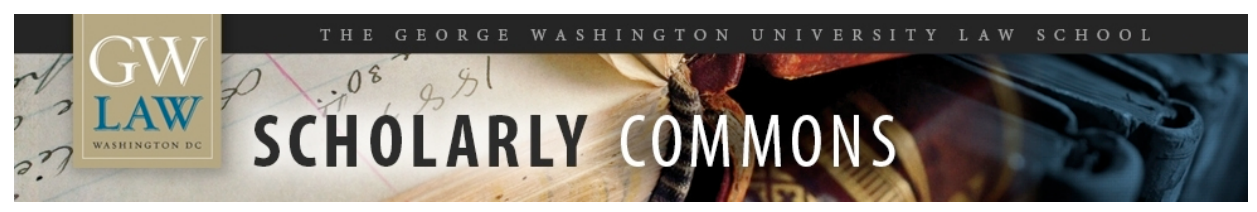

GW Law Faculty Publications \& Other Works

Faculty Scholarship

2013

\title{
Emotional Intelligence and Negotiation Performance
}

Charles B. Craver

George Washington University Law School, ccraver@law.gwu.edu

Follow this and additional works at: https://scholarship.law.gwu.edu/faculty_publications

Part of the Law Commons

\section{Recommended Citation}

Craver, Charles B., "Emotional Intelligence and Negotiation Performance" (2013). GW Law Faculty Publications \& Other Works. 1059.

https://scholarship.law.gwu.edu/faculty_publications/1059

This Article is brought to you for free and open access by the Faculty Scholarship at Scholarly Commons. It has been accepted for inclusion in GW Law Faculty Publications \& Other Works by an authorized administrator of Scholarly Commons. For more information, please contact spagel@law.gwu.edu. 


\title{
EMOTIONAL INTELLIGENCE AND NEGOTIATION PERFORMANCE ${ }^{1}$
}

\author{
Charles B. Craver ${ }^{2}$
}

\section{INTRODUCTION}

For over thirty-five years, I have taught negotiation courses to several thousand law students and over 90,000 practicing attorneys through continuing legal education programs and in-house training programs. Throughout this period, I have frequently thought about personal traits that might influence negotiator performance. I initially sought to determine whether better students - represented by Grade Point Averages (GPAs) - would achieve greater success on negotiation course exercises than less proficient students. Academics generally believe that students with higher GPAs are more intelligent, more conscientious, and more articulate than students with lower GPAs. I initially explored this issue in 1986 and found no statistically significant correlation between student GPAs and negotiation exercise performance. ${ }^{3}$ I reexamined this issue in 2000, and again found no correlation. ${ }^{4}$

I next decided to compare the results achieved on negotiation exercises by male and female students. The impetus for this study came from male law firm partner questions regarding the ability of women to negotiate as effectively as men. They clearly believed that males could achieve better results in tough legal negotiation encounters than their female cohorts. I was concerned that such stereotypical beliefs might undermine the ability of female law students to obtain associate positions and subsequently affect their chances to advance into firm partnerships. Despite some sociologically recognized differences between men and women - some suggesting that males would be more effective negotiators and some suggesting that females would be more effective - I hypothesized that there would be no negotiation result differences based upon gender. In 1990, I published an article finding no statistically significant differences in the results achieved by male and female students on my course exercises. ${ }^{5}$ Nine years later, David Barnes and I reexamined this area and again found no gender-based negotiation result

\footnotetext{
${ }^{1}$ Copyright 2012 by Charles B. Craver.

2 Freda H. Alverson Professor of Law, George Washington University. J.D., 1971, University of Michigan; M. Indus. \& Labor Rels., 1968, Cornell University School of Industrial \& Labor Relations; B.S., 1967, Cornell University. I must express great appreciation for the extraordinary assistance of Dr. Allison Abbe, without whose professional help this project could not have been conducted.

${ }^{3}$ See Charles B. Craver, Clinical Negotiation Achievement as a Function of Traditional Law School Success and as a Predictor of Future Negotiating Performance, 1986 MO. J. DISP. RES. 63 (1986).

${ }^{4}$ See Charles B. Craver, The Impact of Student GPAs and a Pass/Fail Option on Clinical Negotiation Course Performance, 15 OHIO ST. J. DISP. RES. 373 (2000).

5 See Charles B. Craver, The Impact of Gender on Clinical Negotiating Achievement, 6 OHIO ST. J. DISP. RES. 1 (1990).
} 
differences. ${ }^{6}$ I recently evaluated my Legal Negotiation class data for the sixteen years following the study I conducted with David Barnes to challenge an article by Professors Russell Korobkin and Joseph Doherty ${ }^{7}$ which documented a significant difference between the results achieved by male and female law students on a single negotiation exercise given to first year students who had not been given any formal negotiation training. I again found absolutely no statistically significant differences with respect to student performance based upon their gender. ${ }^{8}$

After I read an article discussing the reluctance of black athletes to retain the services of black agents to negotiate their salaries, ${ }^{9}$ I decided to explore any possible correlation between race and negotiation performance. I examined possible sociological differences between blacks and whites that could affect their negotiation performances, and again hypothesized that there would be no statistically significant differences. I evaluated nine years of data from my Legal Negotiation class at George Washington University and found no differences with respect to the negotiation results achieved by black and white students. ${ }^{10}$

The results of my gender and race studies did not surprise me, but the two studies comparing student GPAs and negotiation exercise results did. I had initially expected some positive correlation between student GPAs and negotiation performance. Nonetheless, when I completed my GPA studies, I realized that I might be comparing unrelated personal capabilities. Student GPAs, based primarily upon examination results, measure abstract reasoning skills - the ability of students to learn fundamental rules and concepts and to apply those factors to hypothetical fact patterns. On the other hand, negotiations involve personal interactions in which the ability of individuals to relate effectively to others is of paramount importance.

I thus began to think that if abstract reasoning skills do not meaningfully influence bargaining interactions, interpersonal capabilities might. To evaluate this possibility, I decided to work with psychologist Allison Abbe to determine whether there might be any correlation between emotional intelligence and negotiator performance.

\section{LEGAL NEGOTIATION COURSE METHODOLOGY}

\footnotetext{
${ }^{6}$ See Charles B. Craver \& David W. Barnes, Gender, Risk Taking, and Negotiation Performance, 5 MICH. J. GENDER \& L. 299 (1999). See also Charles B. Craver, Gender and Negotiation Performance, 4 SOCIOLOGICAL PRACTICE 183 (2002).

${ }^{7}$ Russell Korobkin \& Joseph Doherty, Who Wins in Settlement Negotiations? 11 AMER. L. \& ECON. REV. 162 (2009).

${ }^{8}$ See Charles B. Craver, The Impact of Gender on Negotiation Performance, 14 CARDOZO J. CONFLICT RES. _ (2013).

9 See James G. Sammataro, Business and Brotherhood, Can They Coincide? A Search Into Why Black Athletes Do Not Hire Black Agents, 42 HOW. L.J. 535 (1999).

${ }^{10}$ See Charles B. Craver, Race and Negotiation Performance, 8 DISP. RES. MAG. 22 (Fall 2001).
} 
Since the vast majority of legal disputes are resolved through negotiated agreements rather than adjudications, and business relationships are virtually all structured through bargaining interactions, the development of negotiation skills contributes significantly to one's ability to be an effective legal practitioner. During the 1960s, innovative law professors began to recognize that simulation exercises could be employed in clinical courses to teach students how to negotiate. Professors James White at the University of Michigan ${ }^{11}$ and Cornelius Peck and Robert Fletcher at the University of Washington $^{12}$ developed simulation models designed to enhance the negotiating proficiency of future legal practitioners.

Since 1973, I have taught a Legal Negotiation course based upon the White-PeckFletcher models. Over the past twenty-six years, I have taught that class at George Washington University. This is a simulation class during which the students engage in a series of negotiation exercises the results of which determine two-thirds of their course grades. Over the past ten years, I have also taught the one-credit Peter Bronstein Negotiation Institute at the University of Virginia. Since this class has 120 students and only meets on two consecutive Saturdays, all of the students in this course are graded on a credit/no-credit basis. Over the past five years, I have taught a similarly condensed onecredit hour negotiation course at the George Washington University Law School which meets the first four Friday mornings during the Spring Semester, with all of the students being required to take the class on a credit/no-credit basis. The students who take these one hour credit/no-credit intensive courses spend far less time on the exercises than the students in my graded three hour course, and they take those exercises less seriously.

Unlike traditional law school courses in which student grades are indirectly affected by the performance of other students due to the application of specified grading curves, the interactions between students in the Legal Negotiation class directly affect their grades. Some exercises are conducted on a one-on-one basis and some are done on a two-on-two basis. They may encounter personal difficulties with partners or opponents, and these circumstances may adversely affect their interactions. It is thus imperative that they learn to interact successfully with others.

The first class is devoted to an explanation of the course format and the grading process. The students are told that they will explore the negotiation process and engage in a series of negotiation exercises. The initial six or seven exercises are entirely for practice purposes to demonstrate the concepts being taught and to get the students used to the exercise formats. The results of these exercises have no impact on course grades. Students are encouraged to experiment with respect to their bargaining styles to discover

${ }^{11}$ See James J. White, The Lawyer as a Negotiator: An Adventure in Understanding and Teaching the Art of Negotiation 19 J. LEGAL EDUC. 337 (1967). See also HARRY T. EDWARDS \& JAMES J. WHITE, THE LAWYER AS A NEGOTIATOR (1977).

12 See Cornelius J. Peck \& Robert L. Fletcher, A Course on the Subject of Negotiation, 21 J. LEGAL EDUC. 196 (1968). See also CORNELIUS J. PECL, CASES AND MATERIALS ON NEGOTIATION (1980). 
an approach they feel comfortable employing. The relative results of the next six exercises affect two-thirds of their class grades. ${ }^{13}$ Each exercise is structured in a "duplicate bridge" format. Everyone receives identical General Information describing the relevant factual circumstances and the specific issues that must be resolved through the negotiation process. I then provide all of the individuals on the same side with Confidential Information apprising them of the special information possessed by their client, explaining their client's bargaining objectives, and providing numerical values for each of the issues to be addressed. They are thus able to determine exactly how they will be evaluated if they reach agreements and are told what will happen if no accords are achieved. $^{14}$

Students are usually assigned one or two zero-sum problems that only concern the amount of money one side will pay to the other, based upon the fact that many litigation and even some non-litigation - interactions are limited to these types of "distributive" situations that involve head-to-head competition. ${ }^{15}$ They are also assigned a number of non-zero-sum exercises involving various issues that are valued differently by the two parties involved. These permit cooperative negotiators to increase their respective satisfaction levels through efficient "integrative" bargaining designed to maximize the joint returns attained by the parties.

On some exercises, students are assigned partners to assist them with the complex issues involved and to demonstrate the difficulties negotiators may encounter when dealing with persons on their own side. For each exercise, students are randomly assigned different opponents - and, where relevant, different partners. This is done to maximize the number of individuals with whom they will interact throughout the term, and to prevent one student from having an excessive impact on the course grade of another student.

At the conclusion of each exercise, we initially discuss the way in which different issues should have been resolved to maximize the joint returns achieved. Even when the students are working on the exercises that affect their course grades, they are taught to appreciate the fact that the greater the joint surplus they create, the easier it is for them to claim more for their own side. The students are ranked from high to low based upon the total number of points they have achieved for their respective clients. If there are twenty pairs, the highest person on each side receives 20 placement points, the second highest 19

\footnotetext{
13 I drop the lowest of each student's scores, and add up the other five. I have recently reduced the degree to which negotiation exercise results influence course grades to fifty percent.

14 In most cases, they are told that if no agreement is reached, they will be placed at the bottom of all groups on their side. In some cases, however, they are given specific non-settlement options. They may be asked to flip a coin a certain number of times, roll two dice, or pull numbered pieces of paper out of a box. They are told exactly how their results will be determined if one of these options is available to them.

15 See generally Gerald B. Wetlaufer, The Limits of Integrative Bargaining, 85 GEO. L.J. 369 (1996).
} 
placement points, and so forth. ${ }^{16}$ The total number of placement points earned by each student on the five graded exercises on which they earned their best scores is used to determine two-thirds of their course grade. Class members are also required to prepare ten to fifteen page papers exploring the negotiation process. They are asked to analyze their bargaining interactions based upon the concepts covered during the semester. Some papers focus on the negotiation process, the effectiveness of different negotiator styles or bargaining techniques, the impact of race, gender, or similar factors, the use of deceptive tactics, the importance of verbal and nonverbal communication skills, and other similar topics. The scores attained on these papers constitute one-third of course grades.

Students are told that if they work on all of the assigned exercises and prepare acceptable papers, they are guaranteed grades of $\mathrm{C}+$ or better, with most grades in the $\mathrm{B}+/ \mathrm{A}$ - range. Students can take my three hour course on a credit/no-credit basis, but very few have done so over the past fifteen years due to two factors. First is the fact that our enhanced grading curve makes it easy for students to achieve grades of $\mathrm{B}+, \mathrm{A}-$, or higher. The second reason concerns the fact that several years ago we adopted an upper-class skills course requirement that can only be satisfied by students taking such classes for regular grades. Since most of the students currently use my Legal Negotiation class to satisfy this requirement, they almost all take the class for traditional letter grades.

During the first eight to ten weeks of the semester, the students are assigned chapters from Effective Legal Negotiation and Settlement ${ }^{17}$ and are encouraged to read books like Getting to Yes, ${ }^{18}$ Beyond Winning, ${ }^{19} 3-D$ Negotiation, ${ }^{20}$ and Negotiation Genius. ${ }^{21}$ They explore the impact of negotiator styles: the cooperative/problem-solving style; the competitive/adversarial style; and the hybrid competitive/problem-solving style. $^{22}$ I point out the fact that the most successful negotiators are often persons whose opponents think they have been completely open and cooperative, but who admit to being

\footnotetext{
${ }^{16}$ When there are ten groups of four, I assign 20 points to the most successful pair, 18 points to the next pair, sixteen to the next pair, and so forth, to ensure that the two-on-two exercises are worth as much as the one-on-one exercises.

17 CHARLES B. CRAVER, EFFECTIVE LEGAL NEGOTIATION AND SETTLEMENT $\left(7^{\text {th }}\right.$ ed. 2012$)$ [hereafter Craver, Effective Legal Negotiation]. Students in the one credit hour intensive courses taught on four half days at George Washington University and two full days at the University of Virginia are assigned readings from CHARLES B. CRAVER, SKILLS \& VALUES: LEGAL NEGOTIATING (2 ${ }^{\text {nd }}$ ed. 2012).

18 ROGER FISHER \& WILLIAM URY, GETTING TO YES (1981).

19 ROBERT H. MNOOKIN, SCOTT R. PEPPET \& ANDREW S. TULUMELLO, BEYOND WINNING (2000).

${ }^{20}$ DAVID A. LAX \& JAMES K. SEBENIUS, 3-D NEGOTIATION (2006).

21 DEEPAK MALHOTRA \& MAX BAZERMAN, NEGOTIATION GENIUS (2007).

22 See Craver, Effective Legal Negotiation, supra note 17, at 11-18.
} 
not entirely open and somewhat manipulative. ${ }^{23}$ These bargainers recognize the critical nature of the bargaining process. Studies have found that when individuals believe that the negotiation process has been fair and feel that they have been treated respectfully, they are actually more satisfied with objectively less beneficial terms than when they feel the process has not been fair. ${ }^{24}$

The class examines the various stages of the negotiation process. ${ }^{25}$ During the Preparation Stage negotiators must ascertain the relevant factual, legal, economic, and cultural issues, and then determine their own bottom lines, their own goals, and their planned opening positions. They must also try to place themselves in the shoes of their opponents and estimate the goals and bottom lines of those parties. ${ }^{26}$ They must then determine how they picture getting from where they begin to where they hope to end up. They then begin their interactions with opponents during the Preliminary Stage where they seek to establish rapport with the persons on the other side and create positive bargaining environments that are likely to generate relatively cooperative and efficient interactions.

During the Information Stage, negotiators must determine the pertinent issues to be resolved and the underlying interests associated with those terms. This is the "value creation" portion of bargaining interactions, where the parties must ascertain what they have to share with each other. The most effective way to obtain the relevant information from the other side is to initially ask broad, open-ended questions which gets the opposing side talking. ${ }^{27}$ As they get further into this stage, they should shift to "what" and "why" questions, with the "what" inquiries used to determine the specific issues involved, and the "why" inquiries used to discover the opponent interests underlying those particular terms. During this stage, negotiators must be active listeners who look for

23 See Keith G. Allred, Distinguishing Best and Strategic Practices: A Framework for Managing the Dilemma Between Creating and Claiming Value, 16 NEGOT. J. 387, 394-395 (2000). It is also interesting to note that while many people think that cooperative/problem-solvers generate the most efficient joint returns, an empirical study found that individually motivated negotiators produced greater joint outcomes than cooperatively motivated pairs. See Kathleen M. O'Connor \& Peter J. Carnevale, A Nasty But Effective Negotiating Strategy: Misrepresentation of a Common-Value Issue, 23 PERSONALITY \& SOC. PSYCH. BULL. 504, 515 (1997).

24 See Rebecca Hollander-Blumoff, Just Negotiation, 88 WASH. U. L. REV. 381 (2010); Rebecca Hollander-Blumoff \& Tom Tyler, Procedural Justice in Negotiation: Procedural Fairness, Outcome Acceptance, and Integrative Potential, 33 LAW \& SOC. INQUIRY 473 (2008).

25 See Craver, Effective Legal Negotiation, supra note 17, at 53-164.

26 See GRANDE LUM, THE NEGOTIATION FIELDBOOK 58 (2011); LEIGH L. THOMPSON, THE MIND AND HEART OF THE NEGOTIATOR 28-29 ( $3^{\text {rd }}$ ed. 2005); KATHLEEN KELLEY REARDON, THE SKILLED NEGOTIATOR 46-51 (2004).

27 See RONALD M. SHAPIRO, DARE TO PREPARE 113-120 (2008); DEEPAK MALHOTRA \& MAX BAZERMAN, NEGOTIATION GENIUS 40-41 (2007). 
verbal leaks and nonverbal signs suggesting the true interests of the opposing side. ${ }^{28}$ During this portion of bargaining interactions the participants must be relatively open, but they may over- or under-state the value of particular items for strategic purposes. Although Model Rule 4.1 prohibits knowing lawyer misrepresentations of material fact, Comment 2 acknowledges that in the negotiation context statements concerning client values and settlement intentions do not constitute "material" fact, thus allowing negotiators to engage in puffing and embellishment. ${ }^{29}$

Once they complete the Information Stage, the negotiators move into the Distributive Stage, which is the "value claiming" portion of their interaction. During this portion of the bargaining process, they have to divide the surplus they created during the Information Stage, and both sides are usually seeking to claim more than they give up. ${ }^{30}$ Near the end of the Distributive Stage, the participants begin to see the likelihood of an agreement on the horizon, and they enter the Closing Stage. They are still a ways apart, but are becoming psychologically committed to an accord. This is a delicate part of bargaining interactions, because the parties are anxious to conclude their interaction, and the more anxious participant is likely to close more of the remaining gap. They should avoid bidding against themselves with unreciprocated concessions, and should try to move in concert toward final terms.

Once negotiators agree upon final terms, they often think their interaction is over, and prematurely end the bargaining process. Individuals who make this mistake are likely to end up with less efficient terms than they might have achieved if they had moved into the Integrative Stage, which is designed to ensure that the parties have divided the different items in a mutually efficient manner. They should look for items which may have ended up on the wrong side of the bargaining table due to puffing and embellishment. They must try to determine if there is any way they can trade items already agreed upon in a manner which will enable them to expand the overall bargaining pie and simultaneously improve their respective positions. They want to avoid the situation in which they leave potential client gains on the bargaining table.

The importance of verbal and nonverbal communication is stressed, ${ }^{31}$ and psychological factors that influence bargaining interactions are considered. ${ }^{32}$ Different bargaining tactics are also explored. ${ }^{33}$ Specific negotiation issues pertaining to such

${ }^{28}$ We carefully explore "verbal leaks" which inadvertently contain hidden messages and nonverbal signals which also convey important information. See Craver, Effective Legal Negotiation, supra note 17, at 25-52.

29 See Charles B. Craver, Negotiation Ethics for Real World Interactions 25 OHIO ST. J. DISP. RES.299, 306-308 (2010).

${ }^{30}$ See generally Charles B. Craver, The Inherent Tension Between Value Creation and Value Claiming During Bargaining Interactions, 12 CARDOZO J. CONFLICT RES. 1 (2010).

${ }^{31}$ See Craver, Effective Legal Negotiation, supra note 17, at 26-52.

${ }^{32}$ See id. at 30-35.

${ }^{33}$ See id. at 164-212. 
issues as the commencement of settlement talks, telephone and e-mail interactions, dealing with government agencies, and the use of mediators are covered. ${ }^{34}$ The class also evaluates the impact of cultural differences, and students are asked if they think their relationships with partners and/or opponents have been influenced by such factors as race, nationality, or gender. ${ }^{35}$ The class explores the use of "attitudinal bargaining" to modify the unacceptable behavior of some opponents. ${ }^{36}$ Transnational interactions are considered, ${ }^{37}$ and mediation assistance is explored. ${ }^{38}$ We finally revisit negotiation ethics, and the importance of maintaining honorable reputations. ${ }^{39}$

\section{EMOTIONAL INTELLIGENCE}

Professors Peter Salovey and John Mayer have succinctly defined "emotional intelligence" to involve "the ability to perceive accurately, appraise, and express emotion; the ability to access and/or generate feelings when they facilitate thought; the ability to understand emotion and emotional knowledge; and the ability to regulate emotions to promote emotional and intellectual growth." 40 Gerald Matthews, Moshe Zeidner, and Richard Roberts similarly define this concept as "the competence to identify and express emotions, understand emotions, assimilate emotions into thought, and regulate both positive and negative emotions in the self and others." and how does this factor affect bargaining interactions?

34 See id. at $213-258$.

35 See id. at 265-277.

36 See WILLIAM URY, GETTING PAST NO (1991); WILLIAM URY, THE POWER OF A POSITIVE NO (2007).

37 See Craver, Effective Legal Negotiation, supra note 17, at 279-334.

38 See id. at 335-405.

39 See id. at 407-430.

40 John D. Mayer \& Peter Salovey, What Is Emotional Intelligence? in PETER SALOVEY, MARK A. BRACKETT \& JOHN D. MAYER, eds., EMOTIONAL INTELLIGENCE 29, 35 (2004) [hereafter EMOTIONAL INTELLIGENCE]. See Graeme J. Taylor \& R. Michael Bagby, An Overview of the Alexithymia Construct in REUVEN BAR-ON \& JAMES D.A. PARKER, eds., THE HANDBOOK OF EMOTIONAL INTELLIGENCE 40, 44-45 (2000) [hereafter HANDBOOK OF EMOTIONAL INTELLIGENCE]; John D. Mayer, Peter Salovey \& David R. Caruso, Emotional Intelligence as Zeitgeist, as Personality, and as a Mental Ability in HANDBOOK OF EMOTIONAL INTELLIGENCE 92, 109; Jennifer Hedlund \& Robert J. Sternberg, Too Many Intelligences? in HANDBOOK OF EMOTIONAL INTELLIGENCE 136, 146-47; Richard D. Lane, Levels of Emotional Awareness in HANDBOOK OF EMOTIONAL INTELLIGENCE 171-72; Reuven Bar-On, Emotional and Social Intelligence in HANDBOOK OF EMOTIONAL INTELLIGENCE 363, 365; DANIEL GOLEMAN, EMOTIONAL INTELLIGENCE 43, 268, 283-84 (1995). See generally JOSEPH CIARROCHI, JOSEPH P. FORGAS \& JOHN D. MAYER, eds., EMOTIONAL INTELLIGENCE IN EVERYDAY LIFE (2006).

${ }^{41}$ GERALD MATTHEWS, MOSHE ZEIDNER \& RICHARD D. ROBERTS, EMOTIONAL INTELLIGENCE: SCIENCE AND MYTH 3 (2002). 
The first factor concerns the ability of individuals to perceive and express emotions. Even infants and young children learn to identify their own emotional feelings, and to recognize the emotional states being expressed by others. ${ }^{42}$ As persons mature, they generally learn how to monitor their own emotional states. Are they happy, sad, anxious, or tired? By carefully observing the facial expressions and other nonverbal signals emanating from others, they can detect similar moods in those people.

Individuals learn to express their emotional feelings and the personal needs associated with those feelings. ${ }^{43}$ They also develop the ability to differentiate between the honest and disingenuous expression of emotional feelings by other persons. Emotionally intelligent people are able to use their emotional states as aids to judgment. Mood swings from optimistic to pessimistic enable them to contemplate diverse points of view. Their emotional states influence the way in which they solve problems, such as when feelings of happiness encourage inductive reasoning and creativity. ${ }^{44}$

As persons develop more sophisticated levels of emotional intelligence, they learn to understand complex feelings. ${ }^{45}$ Awe is often viewed as a combination of fear and surprise, while hope may result from faith and optimism. People also recognize emotional transitions, such as from anger to satisfaction or from anger to shame. ${ }^{46}$

At the highest level of emotional intelligence, persons develop the capability to manage emotional feelings in themselves and in others. ${ }^{47}$ They appreciate the fact that emotions can be separated from behavior. Mature individuals develop a "meta-experience of mood," which involves two distinct components: "meta-evaluation" and "metaregulation." 48 Meta-evaluation examines "how much attention one pays to one's mood, and how clear, typical, acceptable, and influential one's mood is." 49 Meta-regulation concerns "whether the individual is trying to improve a bad mood, dampen a good one, or leave the mood alone." 50 This capacity enables them to manage their own emotional

\footnotetext{
${ }^{42}$ See Mayer \& Salovey, supra note 40, at 36; Peter Salovey, John D. Mayer \& David Caruso, The Positive Psychology of Emotional Intelligence in EMOTIONAL INTELLIGENCE 61, 64-65.

${ }^{43}$ See Mayer \& Salovey, supra note 40, at 37 Figure 1; Salovey, Mayer \& Caruso, supra note 40, at 64-65.

${ }^{44}$ See id.

${ }^{45}$ See Mayer \& Salovey, supra note 40 , at 38-39.

${ }^{46}$ See id. at 37 Figure 1.

${ }^{47}$ See id.; Salovey, Mayer \& Caruse, supra note 40, at 66; John D. Mayer, Peter Salovey \& David R. Caruso, Emotional Intelligence as Zeitgeist, as Personality, and as Mental Ability in HANDBOOK OF EMOTIONAL INTELLIGENCE 92,102.

48 See Mayer \& Salovey, supra note 40 , at 40.

${ }^{49} I d$.

${ }^{50} \mathrm{Id}$.
} 
feelings. They also develop the ability to express empathy and sympathy for emotions perceived by them in others. ${ }^{51}$

Professors Mayer and Salovey believe that emotional intelligence represents the basic ability people have to reason with emotions - both their own and those of other persons with whom they interact. ${ }^{52}$ When individuals are involved in bargaining encounters, they interact closely with others. Their behaviors are influenced by their own emotional feelings, and those of the people on the other side. Persons may commence interactions with feelings of optimism, as when they are confident that beneficial agreements will be achieved. They may alternatively begin with feelings of pessimism, believing that their chances for success are slim.

People who begin negotiation interactions generally experience some feelings of anxiety. They are not certain that their efforts will be successful, and this uncertainty tends to generate anxiety. Some persons are able to control their anxiety and exude an air of inner peace and confidence that may unnerve more anxious opponents. On the other hand, negotiators who are unable to control these feelings are likely to exude an air of desperation that may be exploited by discerning opponents.

In over thirty-five years of teaching negotiation skills, working as a negotiation consultant, and functioning as a mediator, I have observed and participated in many bargaining interactions. I have found that four factors most often contribute to successful results: (1) the ability to establish firm, but realistic, aspiration levels; (2) the ability to place oneself in the shoes of the opposing side and to appreciate the factors affecting those persons; (3) the capacity to develop and exude an inner confidence in the positions being articulated; and (4) the tendency to ask more questions of opponents than those individuals ask of them. ${ }^{53}$

Before persons commence bargaining encounters with others, they generally confer with the people on their own side. Lawyers try to determine the relevant factual and legal issues, the pertinent economic considerations, and any political and/or cultural influences. They go behind the items initially requested by clients to explore the underlying needs and interests of those persons. They want to understand what their clients really wish to accomplish through the impending interactions. They then have to calculate three critical factors. First, how high or low are they willing to go before they cease negotiating and accept their best alternative to a negotiated agreement (BATNA)? ${ }^{54}$

\footnotetext{
51 See Carolyn Saarni, Emotional Competence in HANDBOOK OF EMOTIONAL INTELLIGENCE 68, 77.

52 See Mayer \& Salovey, supra note 40, at 40.

53 See generally Charles B. Craver, What Makes a Great Legal Negotiator? 56 LOYOLA L. REV. 337 (2010).

54 See Fisher \& Ury, supra note 18, at 104.
} 
Second, how well do they think they can do with respect to each issue to be resolved? There is a direct correlation between aspiration levels and bargaining outcomes.

Individuals who expect to obtain more generous results usually do so compared to persons who begin their interactions with more modest goals. ${ }^{55}$ On the other hand, negotiators must establish realistic expectations. Individuals who begin with wholly unreasonable aspirations either fail to reach any agreements, due to the fact they expect more than their opponents could ever provide, or they ultimately forego their unrealistic goals and fall toward their bottom lines.

The third factor concerns their planned opening positions. Some negotiators like to begin their interactions with modest opening offers, hoping to induce their opponents to reciprocate. Such modest opening position statements are likely to have the opposite effect due to "anchoring." ${ }^{56}$ When persons receive more generous initial offers than they anticipated, they generally increase their own goals, because they think they will achieve better results than they preliminarily thought they could. On the other hand, when they receive less generous offers, they begin to think they will not do as well as they hoped, and they lower their expectations.

Not only do proficient negotiators develop beneficial and rationally defensible aspiration levels, they also develop an inner confidence in the goals they establish. One of my most proficient negotiating students wrote an insightful course paper describing how he developed confidence in his positions. When he was assigned a new exercise, he reviewed the General Information and his side's Confidential Information to appreciate the specific issues to be addressed and the underlying factual and legal considerations. He then tried to determine the best deal he thought he could defend for his own side. He then added something to his side's positions until they seemed unrealistic. He worked on all of the arguments he could employ to defend those exaggerated positions, until he felt comfortable with them. Week after week he obtained extraordinary results from different opponents. At the conclusion of the semester when the class was exploring the traits possessed by the most successful students, several class members suggested that this person was not really that good a negotiator. They said that when they got near the end, "he seemed so sure he was right about his positions, we thought we might be wrong." He was able to exude such an inner confidence in his positions that he induced less confident opponents to defer to his better judgment!

How do proficient negotiators develop the capacity to convince others that they deserve what they hope to attain? Surely part of this factor is reflected in their emotional intelligence. ${ }^{57}$ They learn how to recognize and control their own emotions. When they

55 See Lax \& Sebenius, supra note 20, at 186-87; G. RICHARD SHELL, BARGAINING FOR ADVANTAGE 31-33 (1999).

${ }^{56}$ See Lax \& Sebenius, supra note 20, at 187-89; Russell Korobkin, Aspirations and Settlement, 88 CORNELL LAW REVIEW 1, 30-36 (2002).

${ }^{57}$ See Joseph P. Forgas \& Carrie L. Wyland, Affective Intelligence: Understanding the Role of Affect in Everyday Social Behavior in Ciarrochi, Fogas \& Mayer, supra note 40, 77, 89. 
experience self doubts, they learn to overcome these negative feelings and generate an outward confidence. When they experience anxiety, they learn to exude an inner peace that unnerves more fearful opponents. They closely monitor and react to the emotional feelings of the persons with whom they are interacting. When their opponents seem confident, they subtly work to undermine that optimism. When their opponents seem anxious, they heighten those feelings of anxiety in an effort to make them lower their bargaining expectations.

Another crucial factor concerns the ability of individuals to keep the bargaining process moving forward even when circumstances have become tense. Although some students achieve consistently good results on my course exercises despite negative personal traits, most proficient class members are able to maintain harmonious relationships while they obtain terms that favor their own side. Reputations play a significant role in both my class and in the real world. Tough and even abrasive negotiators may be able to take advantage of anxious and inexperienced opponents who fear the consequences associated with non-settlements, but such persons find it more difficult to accomplish their objectives against skilled opponents who are aware of their negative reputations.

Both in the Legal Negotiation class and in the real world, people communicate about the individuals with whom they have interacted. Persons who monitor and effectively manipulate the emotional fears and feelings of others can frequently obtain generous results for themselves without offending their less successful opponents. ${ }^{58} \mathrm{On}$ the other hand, individuals who generate negative feelings in their opponents are likely to develop negative class reputations. Their future opponents will be informed of their negative traits and work to avoid exploitation by these difficult persons. I have seen class members reject mutually beneficial offers tendered to them merely because of the negative reputations of the persons on the other side.

Based upon the ability of negotiators to understand and control their own emotions during bargaining encounters and their capacity to recognize and influence opponent emotional feelings, one might expect that persons with higher emotional intelligence would be likely to achieve more beneficial negotiation results than individuals with lower emotional intelligence. In this study, we used a detailed questionnaire designed to ascertain the capacity of class members to recognize both their own emotional states and those of others. In addition, we explored the ability of students

\footnotetext{
58 This is especially true in the real world compared with my class. At the conclusion of most bargaining interactions, both sides usually think they have done all right or they would not have agreed to the terms agreed upon. In the real world, there is little chance that less successful bargainers will ever learn how poorly they actually did. In my class, however, the results from each exercise are posted at the conclusion of each exercise. Individuals who may have thought they did quite well when they ended their interactions may discover that they were really cleaned out by their opponents. No matter how agreeably their interactions may have been, this graphic reality often changes their perceptions of the students with whom they negotiated. Nonetheless, it is interesting to note that some students who consistently obtain optimal results for themselves continue to enjoy the respect and admiration of their opponents. Others, on the other hand, become vilified and are described to other class members in quite negative terms.
} 
to control their own feelings and to influence the emotions of others. We wanted to determine whether individuals with higher emotional intelligence had achieved more beneficial negotiation results.

\section{STATISTICAL METHODOLOGY AND FINDINGS}

Dr. Abbe administered an emotional intelligence test to students in my Legal Negotiation classes in 2007, 2008, and 2009. ${ }^{59}$ Participation was entirely voluntary, and the students were assured that I would never know who agreed to participate or the results of their test questions. The test included a number of different questions designed to measure four critical emotional intelligence factors: (1) affective communication; (2) self-monitoring; (3) general emotional intelligence; and (4) Machiavellianism.

The Affective Communication Test (ACT) ${ }^{60}$ assesses nonverbal expressiveness in communication. The ACT consists of thirteen self-report items, such as "I can easily express emotion over the telephone." Nonverbal expressiveness is an aspect of social skill that enables expressive individuals to wield greater influence over others compared to their less expressive cohorts. ${ }^{61}$

The Self-Monitoring Scale ${ }^{62}$ measures one's sensitivity to situational clues and the ability to adapt one's behavior to those cues. The test involves an eighteen item selfreport scale which includes items such as "In different situations and with different people, I often act like very different persons." High self-monitoring individuals are able to control their emotional expressions and social behavior in strategic ways to fit the particular situations and their specific goals.

The term "emotional intelligence" refers to a set of mental abilities that include the recognition, expression, and regulation of one's emotions. ${ }^{63}$ Dr. Abbe assessed emotional intelligence by using a thirty-three item self-report measure, ${ }^{64}$ which included

\footnotetext{
59 After she administered the tests, Dr. Abbe left teaching for a nonacademic position which greatly occupied her time. It was only recently that she was able to perform the relevant statistical evaluations that are reported here.

60 See Howard S. Friedman, Louise M. Prince, Ronald E. Riggio \& M. Robin DiMatteo, Understanding and Assessing Nonverbal Expressiveness: The Affective Communication Test, 39 J. PERSONALITY \& SOC. PSYCH. 333 (1980).

61 See Howard S. Friedman \& Ronald E. Riggio, Effect of Individual Differences in Nonverbal Expressiveness on Transmission of Emotion, 6 J. NONVERBAL BEHAVIOR 96 (1981).

${ }^{62}$ See Mark Snyder, Self-Monitoring of Expressive Behavior 30 J. PERSONALITY \& SOC. PSYCH. 526 (1974).

63 See Mayer, Solovey \& Caruso, supra note 40.

64 See Nicola S.Schutte, John M. Malouff, Lena E. Hall, Donald J. Haggerty, Joan T. Cooper, Charles J. Golden \& Liane Dornheim, Development and Validation of a Measure of Emotional Intelligence, 25 PERSONALITY \& INDIVIDUAL DIFFERENCES 167 (1998).
} 
items such as "I easily recognize my emotions as I experience them." Although selfreport measures of emotional intelligence are only weakly related to performance tests of emotional intelligence, ${ }^{65}$ we were limited to the use of self-reporting due to the practical constraints on this research.

Machiavellianism refers to a tendency toward cynicism in social relationships and a willingness to manipulate others. ${ }^{66} \mathrm{We}$ assessed Machiavellianism with a twenty item self-report measure which included items such as "The best way to handle people is to tell them what they want to hear." Individuals high in Machiavellianism may be more likely to employ manipulative negotiation tactics in pursuit of their own advantage. Research has demonstrated that such individuals will defect, rather than reciprocate, cooperative behavior when it is beneficial to do so. ${ }^{67}$ Such behavior might enable them to generate better terms for themselves than they give to opposing parties.

Dr. Abbe performed the appropriate statistical evaluations, and her results are set forth in the following table. The 2007 and 2008 classes involved my regular three hour graded course, while the 2009 class involved my one hour pass/fail course. No Machiavellianism measures were calculated for the 2007 class members. The numbers in parentheses following each year indicate the number of students who took Dr. Abbe's tests. The p-values represent the degree of statistical significance associated with the reported correlation coefficients for each factor.

\section{EMOTIONAL INTELLIGENCE AND NEGOTIATION RESULTS}

$\begin{array}{lllll}\text { Negot. Class } & \text { Affect. Comm. } & \text { Self-Monitoring } & \text { Emot. Intell. } & \text { Machiavell. } \\ 2007(26) & 0.27(p=0.19) & 0.07(p=0.74) & 0.26(p=0.20) & -- \\ 2008(39) & 0.18(p=0.27) & -0.13(p=0.42) & -0.02(p=0.88) & -0.09(p=0.60) \\ 2009(15) & 0.31(p=0.26) & 0.16(p=0.56) & 0.25(p=0.37) & -0.10(p=0.72)\end{array}$

Empirical findings are considered statistically significant when ascertained pvalues are no higher than 0.10 , with $p$-values of 0.05 being preferred. It is interesting to note that there is not a single factor for which the corresponding $\mathrm{p}$-value even approaches any level of acceptable significance. These findings would clearly negate any suggestion that negotiation results are correlated with emotional intelligence scores.

\footnotetext{
${ }^{65}$ See Marc A. Brackett \& John D. Mayer, Convergent, Discriminant, and Incremental Validity of Competing Measures of Emotional Intelligence, 29 PERSONALITY \& SOC. PSYCH. BULL. 1147 (2003).

${ }^{66}$ See generally RICHARD CHRISTIE \& FLORENCE L. GEIS, STUDIES IN MACHIAVELLIANISM (1970).

${ }^{67}$ See Anna Gunnthorsdottir, Kevin McCabe \& Vernon Smith, Using the Machiavellianism Instrument to Predict Trustworthiness in a Bargaining Game, 23 J. ECON. PSYCH. 49 (2002).
} 
One would expect persons high in emotional intelligence to be more effective when they interact with others, which could be beneficial during the Preliminary Stage of bargaining interactions. ${ }^{68}$ This factor should enhance their ability to establish rapport with opposing parties, and help them create positive negotiating environments. Such persons should also be more adept as discerning the needs of adversaries. ${ }^{69}$ Nonetheless, while emotional intelligence might help to expand the overall surplus to be divided, the results of our study would suggest that this factor does not relate to the their ability to claim more of that surplus for themselves. ${ }^{70}$ As noted earlier, ${ }^{71}$ the most critical factors in this regard concern the ability of negotiators to establish elevated, but realistic, aspirations, and the capacity to develop such confidence in their own positions that they are able to undermine the confidence opponents have in their own positions. These capabilities are more associated with abstract reasoning skills than with emotional intelligence.

The lack of any correlation between emotional intelligence and bargaining outcomes should not suggest that emotional intelligence is irrelevant to skilled negotiators. The ability of individuals to establish rapport and work with others can have a significant effect on their personal reputations and likeability. This should enhance their ability to interact with such adversaries in the future. This is a much better situation than when people have developed such negative reputations that others are wholly adverse to future dealings. This is why negotiation courses should consider the inclusion of emotional intelligence segments designed to enhance the interpersonal skills possessed by the course participants. ${ }^{72}$

\section{CONCLUSION}

Emotional intelligence directly affects the ability of individuals to understand their own emotions and the emotions of others, and their capacity to communicate about

\footnotetext{
68 See Jennifer S. Mueller \& Jared R. Curhan, Emotional Intelligence and Counterpart Mood Induction in a Negotiation, 17 INTL. J. CONFLICT MGT. 110, ’1 (2006).

69 See Ingrid Smithey Fulmer \& Bruce Barry, The Smart Negotiator: Cognitive Ability and Emotional Intelligence in Negotiation, 15 INTL. J. CONFLICT MGT. 245, 259 (2007).

70 See Maw Der Foo, Hillary Anger Efenbein, Hwee Hoon Tan \& Voon Chuan Aik, Emotional Intelligence and Negotiation: The Tension Between Creating and Claiming Value, 15 INTL. J. CONFLICT MGT. 411 (2004) (finding that while emotional intelligence helped to create surplus, it did not help to claim value for one's self); Hillary Anger Elfenbein, Maw Der Foo, Judith White \& Hwee Hoon Tan, Reading Your Counterpart: The Benefit of Emotion Recognition Accuracy for Effectiveness in Negotiation, 31J. NONVERBAL BEHAVIOR 205 (2007) (finding that while higher emotional perception increased the total surplus created by bargaining parties, it was only marginally related to the proportion of that surplus claimed by each party).

71 See note 52, and accompanying text, supra.

72 See Peter Reilly, Teaching Law Students How to Feel: Using Negotiations Training to Increase Emotional Intelligence, 21 NEGOT. J. 301 (2005).
} 
these critical factors. These capabilities can enhance bargaining interactions by helping parties to develop advantageous personal relationships and positive bargaining

environments. Nonetheless, the results of this empirical study have found no statistically significant correlation between emotional intelligence and negotiation exercise outcomes. This does not mean, however, that people who teach negotiation courses should not include segments designed to help students develop a greater appreciation of their emotional intelligence capabilities to help them when they see the same opponents repeatedly. 